\title{
Thorstein B. Veblen Precursor of the Competence-Based Approach to the Firm
}

Foss, Nicolai J.

Document Version

Final published version

Publication date:

1996

License

CC BY-NC-ND

Citation for published version (APA):

Foss, N. J. (1996). Thorstein B. Veblen: Precursor of the Competence-Based Approach to the Firm . DRUID Danish Research Unit for Industrial Dynamics. DRUID Working Paper No. 96-15

Link to publication in CBS Research Portal

\section{General rights}

Copyright and moral rights for the publications made accessible in the public portal are retained by the authors and/or other copyright owners and it is a condition of accessing publications that users recognise and abide by the legal requirements associated with these rights.

\section{Take down policy}

If you believe that this document breaches copyright please contact us (research.lib@cbs.dk) providing details, and we will remove access to the work immediately and investigate your claim. 


\section{$\mathbf{D}_{\text {ANSH }} \mathbf{R}_{\text {ESearch }} \mathbf{U}_{\text {NIt For }} \mathbf{I}_{\text {NDUStriat }} \mathbf{D}_{\text {YNaMics }}$}

DRUID WORKING PAPER NO. 96-15

Thorstein B. Veblen:

Precursor of the Competence-Based

Approach to the Firm

by

November 1996 


\title{
Thorstein B. Veblen: \\ Precursor of the Competence-Based Approach to the Firm
}

\author{
by \\ Nicolai J. Foss \\ Department of Industrial Economics and Strategy \\ Copenhagen Business School \\ Nansensgade 19,6 \\ 1366 Copenhagen $\mathrm{K}$ \\ Denmark \\ Phone +4538152562 \\ Fax +45 38152540 \\ E-mailESNJF@cbs.dk \\ Revised draft, October 17, 1996
}

\begin{abstract}
This paper makes the point that Thorstein Veblen should be considered one of the important precursors of the emerging competence-based approach to the firm. Thus, the emphasis in this literature on firms as path-dependent entities characterised by their heterogeneous knowledgebases, operating under conditions of genuine uncertainty, and existing because they provide moral and cognitive communities that foster the development of productive competencies, can all be traced to key themes in Veblen's work.
\end{abstract}

\section{Acknowledgements}

A number of splendid comments from Geoff Hodgson on an earlier version of this paper are gratefully acknowledged.

\section{Keywords}

Path dependency, competence, uncertainty

\section{JEL Classification}

B15, B25, L22, D81 


\section{Contents}

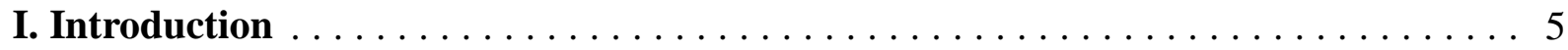

II. The Competence-Based Approach to the Firm: A Signallement $\ldots \ldots \ldots \ldots \ldots$

A. Some Sources of the Competence-Based Approach . . . . . . . . . . . . . 6

B. Main Themes of the Competence-Based Approach $\ldots \ldots \ldots \ldots \ldots \ldots$

III. Competence-Based and Contractual Approaches to the Firm $\ldots \ldots \ldots \ldots \ldots$

A. Overall Perspective: Two Meta-Tales . . . . . . . . . . . . . . . . . . 10

B. Explananda . . . . . . . . . . . . . . . . . . . . . . . 13

C. Knowledge, Production, and the Boundaries of the Firm . . . . . . . . . 14

IV. Thorstein B. Veblen: Precursor of the Competence-Based Approach $\ldots \ldots \ldots 16$

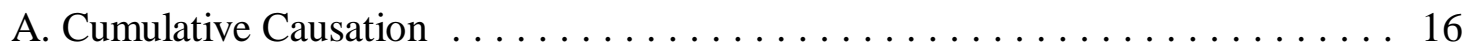

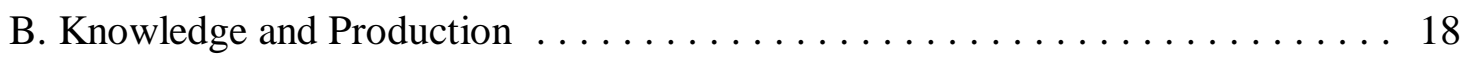

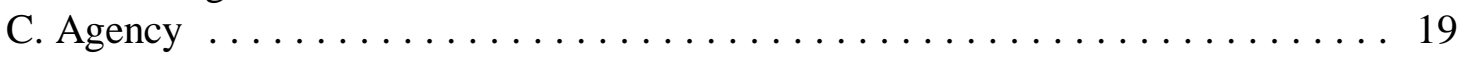

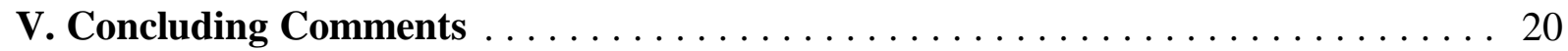

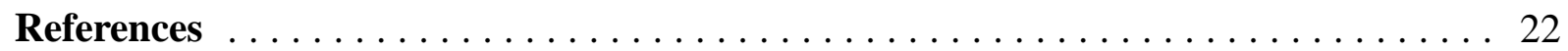





\section{Introduction}

Thorstein Veblen wrote extensively about the business firm and about economic organisation more broadly. He rather ambitiously called one of his major works The Theory of Business Enterprise (1904), but in spite of the title of that book, the fact remains that Veblen never developed a systematic theory of the firm (the same could be said of his institutionalist followers). Instead, he got side-tracked into all other sorts of related issues - such as the industrial/pecuniary dichotomy - some of which were insightful and interesting and some of which were flatly dilettante. Moreover, the reason why Veblen was interested in firms was basically because they were necessary components in his broader arguments about business cycles or the historic transformations from the craft economy to mass production.

Nevertheless, one of my primary aims in this paper is to demonstrate that Veblen should in fact be more generally recognised as a precursor of an important contemporary stream within the theory of the firm, namely what is increasingly often referred to as "the competence-based approach" (henceforth, "the CBA") to the theory of the firm (Foss, 1993; Hodgson, 1996). More specifically, we find in this emerging literature an emphasis on themes that were also crucial in Veblen's thought, such as cumulative causation, the role of knowledge in production, pathdependency, etc. - themes that differentiate this literature from the more orthodox transaction cost literature, akin to the way in which Veblen's introduction of these themes set him aside from the neo-classical economics of his day.

Briefly, the competence-based approach, which has been emerging primarily in the intersection between economics and management studies, emphasises the importance of specific stocks of partly tacit and socially produced and reproduced knowledge - competencies - when accounting for 1) the sources of competitive advantage and 2) economic organisation, such as the existence and boundaries of firms (Langlois, 1992; Foss, 1993; Hodgson, 1996). This differentiates it from the contractual perspective on the firm (Williamson, 1985; Hart, 1995), because this perspective does not fundamentally inquire into the sources of competitive advantage and does not feature competencies as part of the explanatory mechanism. In fact, the CBA may be interpreted as a rivalrous perspective on economic organisation, developed not from essentially orthodox premises, as the contractual perspective, but from evolutionary premises (Foss, 1996a; Hodgson, 1996). 


\section{The Competence-Based Approach to the Firm:}

\section{A Signallement}

The term "the competence-based approach" is a portmanteau label for a number of distinct insights and perspectives, drawn from different discussions, streams of thought and even disciplines that may, nevertheless, be reconstructed as sharing a number of important themes that differentiate them from other approaches to the firm, notably the contractarian approach (Foss, 1993; Hodgson, 1996). The primary common theme is the common-sensual recognition that individuals - and organisations — are necessarily limited in what they know how to do well. Indeed, the main interest of the CBA is to understand what is distinctive about firms as unitary, historical organisations of co-operating individuals and the focus here turn to competencies. Competencies constitute the knowledge base of the firm, and as such belong to the firm level rather than to level of the individual agents. They are normally seen as productive bundles of routines of a highly tacit and social nature (Nelson and Winter, 1982), and they are operated by teams of individuals for some strategic purpose (Penrose, 1959).

While the different discussions and streams of thought reach decades back in time, the realisation that there are a number of shared themes to these streams is a relatively new one. Accordingly, let me here first mention the relevant discussions and streams of thought, before moving on to discussing common themes.

\section{A. Some Sources of the Competence-Based Approach}

Although it is possible to trace key ideas in the CBA back to the division of labour-based production theory of the classical economists (Foss, 1996c; Hodgson, 1996), the key sources of the approach can largely be located at the outskirts of economics, such as in strategic management, technology studies, international business, institutional evolution, and much else (Hodgson (1996b) is probably the most detailed conspectus of precursors of the competencebased approach). I here provide a small conspectus of some important sources of the CBA, in order not only to point out some of the intellectual forebears to the modern CBA, but also to indicate the possibilities of cross-fertilisation between different streams of thought.

How can firms make best use of their distinctive competencies? How have they done this in the past? And how can they go on developing new valuable competencies? Such questions have been central in the firm strategy field since its inception at the end of the 1950s and in the related 
business history field at least since Alfred D. Chandler's (1962) demonstration of the importance of organisational competencies to the restructuring of the American economy that began in the middle of the last century.

The conceptualisation of the firm that underlies this work was perhaps best expressed in Edith Penrose's The Theory of the Growth of the Firm (1959) and explicitly differentiated by her from the prevailing production function view. "The firm", Penrose says, "is...a collection of productive resources the disposal of which between different uses and over time is determined by administrative decision" (Penrose, 1959: 24); a view of the firm that is akin to the strategy view of the firm (Wernerfelt, 1984) and to Chandler's (1990) view.

Now resources in Penrose's view yield services, and it is these services - which is clearly a theoretical precursor to the concept of competencies - that interest her the most. Because resources/services become specialised to firms - and mesh with each other in a team-like manner - they are worth more to the firm than to the market (meaning other firms). They therefore yield Pareto-rents, part of which may be appropriated by the firm's owners. Moreover, although resources/services are firm-specific, they are nevertheless "fungible" inside the firm, and, when in excess, they are stepping-stones for diversifying to new markets.

Finally, the idea of services as something produced endogenously through various intra-firm learning processes represented a powerful argument against the orthodox theory of the firm. In this theory, there is "...no notion of an internal process of development leading to cumulative movements in any one direction" (1959: 1). Rather, growth is simply a matter of adjusting to the equilibrium size of the firm (a critique that also - mutatis mutandis - applies to the contractual theory of the firm). However, as Penrose pointed out,

\footnotetext{
'The attainment of such a 'state of rest' [i.e., equilibrium] is precluded by three significant obstacles: those arising from the familiar difficulties posed by the indivisibility of resources; those arising from the fact that the same resources can be used differently under different circumstances, and, in particular, in a specialised manner; and those arising because in the ordinary processes of operation an expansion new productive services are continually being created" (1959: 68).
}

While there may be optimal rates of growth of firms - specifically, optimal trade-offs between the exploitation of existing resources and the production of new resources - the continuous creation of new knowledge resources through learning effects and the possibility of introducing organisational changes means that firms are never at a "state of rest". In Veblenian terms, there are forces internal to firms that make for cumulative causation. 
Penrose's work helped define at least three distinct areas of research. The first one partially stems from her emphasis that specialised, scarce and valuable resources/services yield rents; this has helped founding what is today referred to as "the resource-based perspective" in contemporary strategy research (Wernerfelt, 1984; Foss, 1997). The main research focus here concentrates on clarifying what must obtain for resources to yield long-lived rents (that is, give rise to sustained competitive advantage). The other area of research is diversification studies (e.g., Dosi, Teece, and Winter, 1992) where the Penrosian theory based on excess competencies is perhaps the dominant economic theory of diversification.

The third area of research that Penrose's work helped to establish is organisational behaviour and learning studies which also owe a heavy debt to seminal contributions to organisation theory such as March and Simon (1958) and Cyert and March (1963). Penrose argued that the management team holds images of the external environment and of the firm's internal resources, that these images are produced through internal learning processes, and that they determine "the productive opportunity set" of the firm, that is, what the firm can see and take advantage of - all ideas that relate to key ideas in contemporary work on organisational behaviour and learning (March, 1988; Marengo, 1995).

Technology studies, broadly conceived, and evolutionary economics are two other, albeit closely related, areas in which anticipations of the CBA can be found. For example, the work of Nathan Rosenberg (1976) emphasised the importance of technological competencies in technological evolution, and the path-dependent process of accumulation of such competencies. In the context of evolutionary economics, competence-based ideas have served - at least since Nelson and Winter's seminal An Evolutionary Theory of Economic Change (1982) - to rationalise the diversity of behaviours, including innovative behaviours, that is necessary in any evolutionary account of industry and technology evolution (Metcalfe, 1989). More broadly, a competence-based conceptualisation of the firm 1) helps rationalise variety, 2) provides an analogy to heredity, and 3) provides the foundation for a theory of differences in revealed competitive advantage, that is, a part of the story of the operation of market selection.

Thus, these ideas have served primarily as a micro-foundation for population analysis of industry and technology evolution, that is to say, as an argumentative stepping-stone in a larger story about phylogenetic change. However, as we saw above, the CBA has also been developed as a more detailed ontogenetic theory of the firm. In its technology-oriented, ontogenetic guise, the competence-based approach has been developed by such writers as Keith Pavitt (1986), Richard Nelson (1994) and Stan Metcalfe (Metcalfe, 1989; Metcalfe and De Liso, 1995). It is worth emphasising, however, that there is no inconsistency between phylogenetic and ontogenetic theories of the firm; what is different is merely the level of analysis and therefore the attention paid to the firm. Thus, more ontogenetically oriented studies, such as Penrose 
(1959), are fully consistent with a broader evolutionary story, such as that contained in Nelson and Winter's (1982) seminal work (cf. Metcalfe, 1989).

\section{B. Main Themes of the Competence-Based Approach}

Given the many and diverse influences that were discussed in the previous section, it may seem to be something of a misrepresentation to talk of "the" competence-based approach in any generic sense. One reason why it does make sense, after all, to do this is that a small but growing number of contributors to the economics of organisation are now self-consciously referring to their work as lying within the confines of a "competence-based", "capabilities" or "resource-based" approach (e.g., Langlois 1992; Kogut and Zander 1992; Foss 1993; Dosi and Marengo 1994; Hodgson, 1996; Langlois and Foss, 1996)

These contributions take somewhat different starting points. Thus, some begin from bounded rationality and other aspects of cognition and build up a theory of firm-specific knowledge - that is, competencies (e.g., Kogut and Zander 1992; Dosi and Marengo 1994). This approach, which draws on theories of organisational learning, has been particularly prevalent among Italian and French evolutionary theorists (e.g., Dosi and Marengo, 1994; Marengo, 1995). Other contributions simply begin from the empirical generalisation that in general productive knowledge is neither explicit nor freely transferable (e.g., Langlois, 1992; Foss, 1993; Langlois and Foss, 1996), without going into the reasons for this in detail.

In what is arguably still a key contribution to the CBA Nelson and Winter (1982: chapter $4 \& 5$ ) explicitly begin with an analysis of individual skills and builds up from this analysis to an analysis of firm-specific intangible assets. The acquisition of skills is a matter of learning by doing and the accumulation of tacit knowledge through the experience of particulars. It therefore opens the door for specialisation, routinization, and predictability; however, the other side of the coin is increased inflexibility. This analysis - drawn from the behavioralist theory of the firm (Cyert and March, 1963) and the work of Michael Polanyi (1958) - is then used as both as a convenient analogy and a micro-foundation for elaborating the idea of organisational knowledge. As Nelson and Winter say, "Routines are the skills of an organization".

More precisely, routines are shared rules of conduct that produce sequences of collective actions over time. Such routines codify organisational and productive knowledge, and are maintained and augmented through application in productive tasks. Like skills, they are partly tacit and imply a certain measure of inflexibility. Thus, firms are repositories of partly tacit and socially produced and reproduced organisation and production knowledge. Because of the role 
of chance, history and lock-in to specific learning domains in the process of knowledgeaccumulation, firms" knowledge-bases are strongly path-dependent and different across the population of firms. Because stocks of knowledge are different across firms, these stocks are associated with different efficiencies, and therefore yield differential rents when deployed to product markets. Thus, the CBA forms the basis of a theory of firm strategy (Wernerfelt, 1984; Dierickx \& Cool, 1989; Foss, 1997).

However we justify the CBA it boils down to the same common-sensual recognition, namely that individuals - and organisations - are necessarily limited in what they know how to do well. Thus, the CBA is a modern-day heir to classical economists' emphasis on specialisation. And like the classical economists, notably Adam Smith, proponents of the CBA emphasises that there are two sides of the specialisation coin: on the one hand, specialisation furthers productivity and inventiveness within given areas, on the other hand, specialisation lowers adaptiveness. As we have seen, this has important implications for such management issues as the efficient level of diversification and the pursuit of competitive advantage through concentration of selected core business areas.

Moreover, it is becoming an increasingly widespread recognition among contributors to the CBA that the approach has fertile implications not only for the understanding of the sources of firm heterogeneity, competitive advantage, and differential rents, but also for the economics of organisation. This is discussed in the following section.

\section{Competence-Based and Contractual Approaches to the Firm}

\section{A. Overall Perspective: Two Meta-Tales}

In a recent paper, Giovanni Dosi (1995) argued that within the social sciences, and therefore also economics, there are two rivalrous meta-tales. One of these is the rationalist, strongly methodologically individualist approach associated today with orthodox economics. It was this meta-tale that was up or attack in so many of Veblen's writings. The ultimate primitives are here preferences, endowments and technologies, while institutions and organisations are derived entities - derived, that is, in a classic functionalist manner as efficiently solving allocational problems for the agents that are involved with the relevant institutions and organisations. At least in economics, this meta-tale is accompanied by analytical closure, that 
is, the stipulation that novelties cannot be allowed for.

In the other meta-tale, which we may safely associate with Veblen, institutions are the ultimate primitives, and preferences, cognition, and the very notion of rationality are derived entities. The mode of explanation here is evolutionary. For example, "explaining firms" would not mean pointing to the role of firms as efficient solutions to some incentive-compatibility problem at a given point of time (although elements of this could enter into the explanation on a secondary level), as in the contractual approach. The reliance on functionalism is one reason for the lack of attention to dynamic issues in the contractual approach, since functionalism (at least in its hard versions) implies the legitimacy of tucking away the generative mechanisms that produce the relevant institution/organisational form.

In the more explicitly orthodox versions of the contractual approach - notably principalagency theory - functionalist methodology is not directly invoked; instead, contracts are being seen as designed on an intentional, ex ante basis. Basically, much of this work represents an attempt to make more "realistic" the arguably still dominant orthodox model, the ArrowDebreu. However, although imperfect and incomplete information - and therefore transaction costs - is formally introduced, closure is still preserved.

As normally used in orthodox theory, asymmetric and imperfect information and the transaction costs they imply are properties of a decision problem that is designed by the theorist as confronting some agent on an ex ante basis. The design of some institution, organisation or contract is the ex post outcome. Typically, this outcome remains efficient, reflecting the analytical closure. Although Williamson's brand of the contractual approach may admittedly not be characterised by the same extreme closure as principal-agent theory (Foss, 1994a), his conception of the economic problem is not in substance different: the economic problem is essentially conceptualised as a matter of combining given inputs in an incentive compatible and transaction cost minimising way. Governance structures are assumed to arise in a basically unexplained way to undertake these tasks.

As Sidney Winter (1988: 192) points out, this functionalism is problematic, because "...the size of a large firm at a particular time is not to be understood as the solution to some organisational problem. General Motors do not sit atop the Fortune 500...because some set of contemporary cost minimisation imperatives (technological or organisational) require a certain chunk of the US economy to be organised in this way". Rather, explaining General Motors' position means looking at its position at time (t-1), (t-2), etc., and telling a dynamic story about how one got from these earlier periods of time to the present: "Its position at the top reflects the cumulative effect of a long string of happenings stretching back into the past, among which were the achievement of relatively good solutions to various technological and organizational 
problems" (ibid.).

While the contractual - or perhaps better: contractarian (Bowles, 1985) - theory of the firm clearly exemplifies the first meta-tale, the CBA may arguably be seen as an instance of the second meta-tale. While the first claim is uncontroversial, the second may be more controversial, and there may be proponents of the CBA that are likely to disagree with it.

However, we should recognise that the two meta-tales alluded to in the above are ideal types and that criticising extreme methodological individualism does not bring us directly into the camp of methodological holism. Instead, we can adopt the position of what Hodgson (1993) calls "organicism" - the idea that individuals both constitute, and are constituted by, society. In fact, organicist ideas have often been invoked in connection with the firm, albeit much more often within management studies (e.g., Sandelands and Stablein, 1987) than within the economic theory of the firm and often implicitly. For example, almost anything that has been written on business culture, has essentially been about how leadership may mould preferences and beliefs and the implications for competitive advantage that this has. The Penrosian idea of the firm's image (as discussed in section II.a. above) is also a reflection of methodological organicism, because it explicitly recognises that not only do agents have to make sense of their world, but their cognitive development is moulded in social processes.

To the extent that orthodox economists have been concerned with phenomena such as business culture and the like, what has been highlighted is the incentive and the signalling role of corporate cultures. Thus, a corporate culture may implicitly define a reward and punishment system and may signal to employees and outside agents (suppliers, customers) that the firm will not opportunistically take advantage of them (Kreps, 1990). But corporate cultures and the like are not seen as influencing preferences and beliefs. Of course, this is not surprising since the idea of intra-firm moulding of behaviours is at conflict with the under-socialised conception of agents and agency to which most economists still cling.

Admittedly, the no-changes-in-preferences-and-beliefs assumption greatly simplifies analysis of economic organisation. For it implies that agents can be assumed to hold the same model of the world, to share "habits of thought", in Veblen's terms. And this in turn implies that a great many real-world intra-firm co-ordination problems can be shunted. However, it may also mean that essential features of the firm are missed. Notably, firms' role as cognitive communities - a key idea in contemporary organisation theory (March, 1988; Marengo, 1995) -- becomes virtually incomprehensible. 


\section{B. Explananda}

The argument that "the knowledge dimension" is absent in the contractual approach to the firm may be met very simply by proponents of this approach: they may retort that these theories are not at all concerned with, for example, the role of knowledge in production. Instead, they are concerned with explaining the existence, the boundaries, and the internal organisation of firms (and other types of economic organisation) (cf. Holmström and Tirole, 1989); issues that would not seem to be highlighted in contemporary evolutionary work on the firm, such as the CBA. Instead, this body of work is taken up with addressing issues such as knowledge accumulation, utilisation, diffusion, etc. Because the theories do not share domains of applications, the charge of neglecting knowledge is pointless

However, for several reasons, this rebuttal is too facile. First, one may argue that there are Grand Questions that any theory of the firm should approach, such as, Why are firms different? Or, Why do they exhibit different rates of growth? Or, Why do firms, even within the same industry, have such divergent strategies, boundaries, organisational structures, etc.? Etc. By concentrating on "mere damage control under conditions of market failure" (Ghoshal et al., 1995: 756), the modern contractual theory of the firm can at most provide a part of the explanation of such Grand Questions; it cannot be a complete theory of the firm.

Second, one may argue that there are real-world phenomena relating to firm organisation that are hard to approach and comprehend if the theory that is applied only puts the emphasis on incentive alignment and has nothing to say about, for example, knowledge accumulation. An example is the dynamics of firms' diversification patterns, which would seem to necessitate that attention are paid to both knowledge-accumulation and transaction cost considerations (cf. Dosi, Winter and Teece, 1992).

Third, it is no longer the case that the evolutionary and the contractual theories of the firm do not share domains of applications. As I have argued at length elsewhere (Foss, 1996a), it is increasingly the case that evolutionary economists are addressing questions traditionally associated with the contractual approach. Thus, we now have a small, albeit growing, collection of evolutionary theories of the existence, the boundaries, and the internal organisation of firms - that is, the key issues investigated in the transaction cost/contractual approach. I briefly discuss this in the following section. 


\section{Knowledge, Production, and the Boundaries of the Firm}

As many critics have pointed out, by focusing on the individual transaction (in the case of Williamson) or contract (in the case of principal-agent theory) as the relevant units of analysis, the contractual approach has difficulties understanding the various (social) networks in which transactions and contracts are embedded. Since the linkedness of transactions is easily missed, the contractual approach has difficulties accounting for the firm as a distinct, historical entity - it is merely held together by the thin glue of transaction cost minimisation.

However, it is not individual transactions, but the firm-specific network of socially produced and reproduced routines that are the primary vehicles of historicity (Chandler, 1992). A potential reason for the ahistorical character of the contractual approach is that underneath it lies the atomistic, under-socialised conception of agency characteristic of orthodox economics. Another important reason, and the one under consideration here, is the separation of production and governance, and the lack of attention to issues of production.

As Harold Demsetz (1988) has argued at length, there is an underlying assumption in the contractual approach that while knowledge for management (governance) purposes is scarce and costly, knowledge for production purposes is assumed to be free; as a result, decisions on the boundaries of the firm - and, indeed, other aspects of economic organisation - cannot turn on considerations of production costs. It has become an increasingly widespread recognition, however, that much knowledge - including, importantly, much knowledge about production - is tacit, that is, not given to direct articulation. Moreover, knowledge about production is often essentially distributed knowledge, that is to say, knowledge that is only mobilised in the context of carrying out a multi-person productive task, and cannot be held by any single agent. These characteristics clearly apply to competencies.

In a world of differential competencies, firms will not confront the same production costs for the same type of productive activity (Richardson, 1972). Moreover, here the costs that can make transacting difficult — the costs that may lead to internalisation or various other business institutions - may go beyond those that arise in the course of safeguarding against opportunism or damping moral hazard through monitoring or incentive contracts. In such a world, economic activity may be afflicted with Richard Langlois (1992) has called "dynamic transaction costs", the costs that arise in real time in the process of acquiring and co-ordinating productive knowledge and which are different in nature from the transaction costs that are caused by problems of aligning incentives.

The first economist to explicitly suggest that competencies should be seen as determinants of economic organization, particularly the boundaries of firms, was George 
Richardson (1972). In Richardson's scheme, production can be broken down into various stages or activities. Some activities are similar, in that they draw on the same general capabilities. Activities can also be complementary (in both a technical and an economic sense) in that they are connected in the chain of production and therefore need to be co-ordinated with one another. Juxtaposing different degrees of similarity against different degrees of complementarity produces a matrix that maps different types of economic organisation. For example, closely complementary and similar activities are best undertaken under unified governance.

Richardson's insight is a simple, but extremely profound, one. For it brings together two crucial issues that both relate to production knowledge, namely, first, the imperfectness of knowledge about how to produce, and, second, the problem of coordinating production knowledge. In fact, the former problem largely creates the latter problem: problems of economic organisation may crucially reflect that one firm controls production knowledge that is, in important dimensions, strongly different from that controlled by other firms. These other firms quite literally may not understand what the firm wants from them, for example, in supplier contracts, or offers them, for example, in license contracts. The reason? The extreme specificity and tacitness of much productive knowledge, which not only means that other firms may have difficulties understanding the firm's capabilities, but also that the firm itself may know more than its contracts can tell (Kogut and Zander, 1992; Langlois, 1992). In this setting, the costs of making contacts with potential partners, of educating potential licensees and franchisees, of teaching suppliers what it is one needs from them, etc. become very real factors behind firms choosing their efficient boundaries.

Somewhat similar ideas may also be applied to a rationalization of the existence of firms. Thus, firms exist, not because they align incentives more efficiently in certain situations (e.g., under team-production), but because they are more efficient institutional structures for the accumulation of competencies than the market. The combination of a framework of incomplete contracts, hierarchical direction and "local" social norms assists social learning processes related to specific types of productive activities (Kogut and Zander, 1992). Thus, firms exist in terms of what they are good at, namely providing moral and cognitive communities that further the accumulation of productive competencies (Ghoshal et al., 1995).

The upshot of all this, we suggest, is that there now exists a distinct basis - a collection of ideas, concepts and mechanisms - for the CBA as a theory of economic organisation, at least with respect to the boundaries of the firm. The following section argues that the work of Thorstein Veblen anticipates key ideas in this emerging perspective. 


\section{Thorstein B. Veblen: Precursor of the Competence-Based Approach}

I shall not here try to give the full picture of Veblen as a precursor of modern evolutionary economics - that has been done by others elsewhere (Hodgson, 1993; Argyrous and Sethi, 1996)) - but rather concentrate on those aspects that have a direct bearing on the theory of the firm. Neither shall I provide an overview of Veblen's many writings on the firm, but rather concentrate on how key Veblenian ideas anticipate ideas associated with the CBA - ideas that differentiate the CBA from the contractual approach to the firm in much the same way that Veblen's ideas differentiated him from his marginalist contemporaries.

To recapitulate, where the CBA differs most obviously from the contractual approach to the firm lies in 1) an explicit treatment of knowledge in production, including a treatment of both the endogeneity and path-dependency of this knowledge, 2) a treatment of social relations in firms, 3) more explicit recognition of genuine uncertainty, lacking knowledge, and the dynamics that give rise to these, and 4) an understanding of economic organization in terms of differential competencies. In the following I connect these themes to key themes in Veblen's thought.

\section{A. Cumulative Causation}

As Hodgson (1993: 129) has indicated, Veblen's preference for the evolutionary metaphor was to a large extent steered by his wish to theorize cumulative causation, or self-propelled change, in which there is no end-state predetermined by "technology, preferences and It is appropriate to begin with the notion of cumulative causation. For endowments" - in short, no equilibrium. Clearly, the evolutionary metaphor is a convenient (if not the only) way of focusing the idea of cumulative causation, because there need not be any equilibrium for evolutionary processes; all sorts of mechanisms may operate to interrupt any tendency towards a presumed equilibrium. As Veblen argued:

“...an evolutionary economics must be a theory of a process of cultural growth as determined by the economic interest, a theory of a cumulative sequence of economic institutions stated in terms of the process itself' (1898a: 77).

In terms of explanation, a theory of cumulative causation may therefore be interpreted as a statement of the workings and interplay of the evolutionary mechanisms, such as the 
evolutionary trinity of selection, variation and heredity. This would therefore seem to be at variance with equilibrium explanations of market outcomes and functionalist explanations of organisations and institutions, such as modern contractual theories of the firm. There is a striking resemblance between the critique of the functionalism of contractual theories by, for example, Winter (1988), and Veblen's critique of the functionalism associated with the marginalist economics of his day. Veblen's approach was

"...to know and explain the structure and functions of economic society in terms of how and why they have come to be what they are, not, as so many economic writers have explained, in terms of what they are good for and what they ought to be" (Veblen, 1901: 267).

Whereas Veblenian ideas of cumulative causation were later discussed by Allyn Young, Gunnar Myrdal, Nicholas Kaldor, Ragnar Nurkse and others, these applications centered on the level of the economic system as a whole. Because of economists" traditional lack of interest in the firm per se, few economists have applied something like the notion of cumulative causation to the firm. Although Alfred Marshall was in this respect non-traditional - his work combined a static notion of industry equilibrium with a dynamic notion of firm growth and decline - his knowledge-based underpinning of firm development was swept aside in the 1920s and 1930s with the hardening of the orthodox research programme on the firm in the hands of Pigou, Robertson, Viner and others. With their work, firms (in an industry) became conceptualised as essentially identical (save, perhaps, for scale) and as always being in equilibrium.

One of the strongest critiques of this conceptualisation emerged in the work of Penrose (1959), as we have seen. Her point that there is an inherent tendency for firms - through various learning processes - to accumulate excess resources, and to put these to profitable use through diversification is a strong statement of cumulative causation at the work of the level of the individual firm. Other contributors to the CBA approach have adopted similar positions (e.g., Dierickx and Cool, 1989; Dosi, Winter and Teece, 1992). In contrast endogenously created change and cumulative causation are conspicuous by their absence from the contractual approach. In this respect, the CBA is the modern heir to Veblen's explanatory approach, along with the evolutionary economics movement, of which the CBA is arguably an important part. 


\title{
B. Knowledge and Production
}

In Veblen's work, cumulative causation is closely connected to changes in productive knowledge:

\begin{abstract}
"There is the economic life process still in great measure awaiting theoretical formulation. The active material in which the economic process goes on is the human material of the industrial community. For the purpose of economic science the process of cumulative change that is to be accounted for is the sequence of change in the methods of doing things - the methods of dealing with the material means of life" (Veblen, 1898: 71)
\end{abstract}

Veblen goes on to criticise contemporary marginalist economics for conceiving of capital as only physical goods ("a mass of material objects"). Again, the connection to cumulative causation is made explicit, for a primary charge against the materialistic conception of capital is that it hinders the development of a theory of cumulative causation (ibid.). On the other hand, if knowledge is explicitly introduced as a productive factor, the door is opened to a theory of cumulative causation because of the inherent tendency of knowledge to change. As he says:

\footnotetext{
"...when taken as items in a process of cumulative change...productive goods are facts of human knowledge, skill and predilection; that is to say, they are, substantially, prevalent habits of thought, and it is as such that they enter into the process of industrial development...it is the human agent that changes, his insight and his appreciation of what these things can be used for is what develops" (Veblen, 1898a: 71).
}

Although the argument refers to the economy-level, there is a striking resemblance between Veblen's argument that the inherent tendency to growth of knowledge is a mechanism behind cumulative change and Penrose's later argument which refers to the firm, but in reality makes exactly the same point.

Knowledge is thus "the motor force in economic development" (1898a: 72), but it is also an important factor in industrial organisation:

"Production takes place only in society - only through the co-operation of an industrial community. This industrial community may be large or small; its limits are somewhat vaguely defined; but it always comprises a group, 
large enough to contain and transmit the traditions, tools, technical knowledge, and usages without which there can be no industrial organisation and no economic relation of individuals to their environment. The isolated individual is not a productive agent...There can be no production without technical knowledge... and there is no technical knowledge apart from an industrial community" (Veblen, 1898b: 34).

Thus, it not only that production requires the co-ordination of different competencies; it is also that the character of these competencies would seem to define boundaries between industrial "groups", because what defines industrial communities and groups as historical entities is their ability to "contain and transmit" productive knowledge. Similar points are also made in Veblen's 1914 book on The Instinct of Workmanship, in which he argues that the industrial skill of a nation consist in a complex, distributed and complementary constellation of habits and routines that reflect national culture.

This is close indeed to the perspective on firms in the CBA as entities in which their role as moral and cognitive communities are inseperable from their role as storehouses of productive knowledge. And it is not so very far from the view that a primary purpose of economic organisation lies in the co-ordination of complementary and dissimilar competencies (Richardson, 1972) - a view that is a hallmark of the CBA. Moreover, it is in the strategyoriented part of this modern literature (such as Dierickx and Cool, 1989) that we find the refinement of the Veblenian idea that there is a close link between "differential business advantage" and "intangible assets" (Veblen, 1908: 363).

\section{Agency}

In many ways, the model of agency employed in the CBA differs strongly from that employed in the contractarian approach, although the former is seldom made wholly explicit by contributors to the CBA. However, there has been a growing interest in founding competencebased ideas about firm-specific knowledge and learning on models of agency that make an explicit break with orthodox conceptualizations of behavior (e.g., Dosi and Marengo, 1994). Thus, the agents that populate the firms of the CBA are constrained by norms and they follow routines, all clearly reminiscent of Veblen's points that "The economic interest does not act in isolation" (1898a: 477) and that behaviour in general should be understood as crucially influenced by the various "traditions, conventionalities, and material circumstances" with which individuals are faced. 
Moreover, these agents are exposed to novelties; indeed, sometimes they introduce novelties themselves, namely in the form of innovations. While Veblen did not use notions such as "novelty" - for example, in the form of new ideas, new routines, technological innovations, etc. - such notions are implied in his emphasis on the role of technology and new knowledge as the motors in economic development and through his concept of "idle curiosity". Of course, his whole Darwinian outlook also harmonises with an emphasis on novelty.

More specifically, Veblen criticised marginalist economists for supposing that “...the human material with which the inquiry is concerned is conceived in hedonistic terms; that is to say, in terms of a passive and substantially inert and immutably given human nature (1898a: 73). In Thomas Sowell's (1967: 128) interpretation of Veblen, Veblen did not argue that such conceptualisations of human nature were inadequate for all purposes, but rather that it was inadequate for analysing creative change. This interpretation certainly has some force, for Veblen (1900b: 176-177) also criticised contemporary marginalist economists for only indicating "...the conditions of survival to which any innovation is subject, supposing the innovation to have taken place, not the conditions of variational growth". This does indeed sound like a precursor to the modern evolutionary critique of the treatment of technological change in orthodox theory. And like modern evolutionary economists, Veblen may be argued to have been reaching for a theory of why and how innovations take place, although this aspect, as so much else in his work, had the character of suggestions and hints rather than worked out ideas.

\section{Concluding Comments}

Why did we have to wait until the work of Penrose (1959) before something resembling the modern CBA crystallised? An important part of the explanation of this undoubtedly has to do with the emergence of the new value theory in the nineteen-thirties, both in its Cambridge neoclassical form and in its Walrasian form.

Within the theory of the firm, the breakthrough and gradual hardening of this sort of theorising meant that all of that in earlier theorising that was "historical", "developmental", perhaps even "evolutionary", was swept aside in favour of identical equilibrium firms. Marshall's industrial analysis was an evident victim of the victorious advent of the new value theory. But so was Veblen's. In fact, the rules of the game changed so radically that Veblen's simply wasn't considered an economist any longer. An implication was that his strictures against orthodox economics and his attempt to construct, however loosely, an evolutionary alternative could be safely neglected. He was remembered as a social critic primarily, and when 
he was mentioned in economics discourse, it was mostly on account of his presumed inability to write clearly.

There was a substantial loss of content here; for although the critics of Veblen have a point when they point out the dilettante and unsystematic nature of much of his work, Veblen did have profound insights in, for example, the role of knowledge in production and pathdependency, insights that we can better appreciate through the lens provided by the CBA. We may also note that Veblen's institutionalist followers failed to elaborate these insights, but why this is so is beyond the scope of the present paper. One hint could be that Commons' emphasis on the transaction as the relevant unit of analysis may be interpreted as a shift from production to exchange, from knowledge and competencies towards transactions.

Thus, ironically Veblen's followers helped pave the way for a body of work - the contractarian theory of the firm - which is, if not diametrically opposed to it, then certainly strongly at variance with Veblen's thought. Moreover, the one economist writing about the firm at about Veblen's time who could have developed an evolutionary theory of the firm, namely Frank Knight (e.g., 1921: 268-9), failed to do so, and was strongly critical of Veblen (idem.: 189n, 334n), although they in reality shared a basic evolutionary outlook. 


\section{References}

Argyrous, George and Rajiv Sethi (1996), "The Theory of Evolution and The Evolution of Theory: Veblen's Methodology in Contemporary Perspective", Cambridge Journal of Economics, 20, 475-495.

Bowles, Samuel (1985), "The Production Process in a Competitive Economy", American Economic Review, 75, 16-36.

Chandler, Alfred D. (1962), Strategy and Structure. Cambridge: MIT Press.

Chandler, Alfred D. (1992), "Organizational Capabilities and the Economic History of the Industrial Enterprise", Journal of Economic Perspectives, 6, 79-100.

Cyert, Richard and James G. March (1963), A Behavioral Theory of the Firm, Englewood Cliffs: Prentice-Hall.

Demsetz, Harold (1988), "The Theory of the Firm Revisited", in idem. (1990), Ownership, Control and the Firm: The Organization of Economic Activity, Oxford: Basil Blackwell.

Dierickx, Ingemar and Karel Cool (1989), "Asset-Stock Accumulation and Sustainability of Competitive Advantage”, Management Science, 35, 1504-1511.

Dosi, Giovanni (1995), "Hierarchies, Markets and Power: Some Foundational Issues on the Nature of Contemporary Economic Organizations", Industrial and Corporate Change, 4, 1-19.

Dosi, Giovanni and Luigi Marengo (1993), "Some Elements of An Evolutionary Theory of Organizational Competences", in Richard W. Englander (ed.) (1993), Evolutionary Concepts in Contemporary Economics, Ann Arbor: The University of Michigan Press.

Dosi, Giovanni, Sidney G. Winter and David J. Teece (1992), "Towards a Theory of Corporate Coherence," in Giovanni Dosi, Roberto Giannetti and Pier-Angelo Toninelli. Technology and Enterprise in a Historical Perspective. Oxford: Clarendon Press.

Foss, Nicolai J. (1993), "The Theory of the Firm: Contractual and Competence Perspectives", Journal of Evolutionary Economics, 3, 127-144.

Foss, Nicolai J. (1994a), “The Two Coasian Traditions”, Review of Political Economy, 5, 3561.

Foss, Nicolai J. (1994b), "Realism and Evolutionary Economics", Journal of Social and Biological Systems, 17, 21-40.

Foss, Nicolai J. (1996a), "Firms, Incomplete Contracts, and Organizational Learning”, Human 
Systems Management, 15, 17-26.

Foss, Nicolai J. (1996b), "Evolutionary Theories of the Firm: Reconstruction and Relations to Contractual Theories", forthcoming in Kurt Dopfer, ed. (1997), Evolutionary Principles of Economics, Boston: Kluwer.

Foss, Nicolai J. (1996c), "The Classical Theory of Production and the Capabilities View of the Firm", forthcoming in Journal of Economic Studies.

Foss, Nicolai J. (1997), Resources and Strategy: A Reader, Oxford: Oxford University Press.

Ghoshal, Sumantra, Peter Moran and Luis Almeida-Costa (1995), "The Essence of the MegaCorporation: Shared Context, Not Structural Hierarchy”, Journal of Institutional and Theoretical Economics, 151, 748-759.

Hart, Oliver D. (1995), Firms, Contracts, and Financial Structure, Oxford: Clarendon Press.

Hodgson, Geoffrey M. (1993a), Economics and Evolution: Bringing Life Back Into Economics, Oxford: Polity Press.

Hodgson, Geoffrey M. (1993b), “Thorstein Veblen and Post-Darwinian Economics”, in idem. (1993a).

Hodgson, Geoffrey M. (1996), "Evolutionary and Competence-Based Theories of the Firm", unpublished $m s$.

Holmström, Bengt R. and Jean Tirole (1989), "The Theory of the Firm", in Richard Schmalensee and Robert D. Willig (eds.) (1989), Handbook of Industrial Organization, Amsterdam, North-Holland.

Kogut, Bruce and Udo Zander (1992), "Knowledge of the Firm, Combinative Capabilities, and the Replication of Technology," Organization Science, 3, 383-397.

Knight, Frank H. (1921), Risk, Uncertainty, and Profit, reprint 1965, New York: Augustus M. Kelley.

Kreps, David M. (1990), "Corporate Culture and Economic Theory", in James E. Alt and Kenneth Shepsle, eds., Perspectives on Positive Political Economy, Cambridge: Cambridge University Press.

Lane, David, Franco Malerba, Robert Maxfield and Luigi Orsenigo (1996), "Choice and Action", Journal of Evolutionary Economics, 6, 43-76.

Langlois, Richard N. (1992), "Transaction-Cost Economics in Real Tim”, Corporate and Industrial Change, 1, 99-127.

Langlois, Richard N. and Nicolai J. Foss (1996), "Capabilities and Governance: the Rebirth of 
Production in the Theory of Economic Organization", unpublished ms.

March, James G. (1988), Decisions and Organizations, Oxford: Basil Blackwell.

Marengo, Luigi (1995), "Structure, Competence, and Learning in Organizations", Wirtschaftspolitische Blätter, 6, 454-464.

Metcalfe, J. Stan (1989), "Evolution and Economic Change", in Aubrey Silberston, ed., Technology and Economic Progress, Basingstoke: Macmillan.

Metcalfe, J. Stan and N. De Liso (1995), "Innovation, Capabilities and Knowledge: The Epistemic Connection", unpublished ms.

Nelson, Richard R. (1991), "Why Do Firms Differ; and How Does It Matter?", in Richard P. Rumelt, Dan E. Schendel, and David J. Teece (1994), Fundamental Issues in Strategy, Boston: Harvard Business School Press.

Nelson, Richard R. and Sidney G. Winter (1982), An Evolutionary Theory of Economic Change, Cambridge: Bellknap Press.

Pavitt, Keith (1986), “Technology, Innovation, and Strategic Management”, in John McGee and Howard Thomas, eds., Strategic Managament Research: A European Perspective, New York: John Wiley.

Penrose, Edith T. (1959), The Theory of the Growth of the Firm, Oxford, Oxford University Press.

Polanyi, Michael (1958), Personal Knowledge, Chicago: University of Chicago Press.

Rosenberg, Nathan (1976), Perspectives on Technology, Cambridge: Cambridge University Press.

Sandelands, L.E. and R.E. Stablein (1987), "The Concept of Organization Mind", in S. Bacharach and N. DiTomaso, eds., Research in the Sociology of Organizations, Vol. 5, Greenwich: JAI Press.

Sowell, Thomas (1967), "The 'Evolutionary' Economics of Thorstein Veblen", in John Cunningham Wood (1993), Thorstein Veblen: Critical Assessments, London: Routledge.

Veblen, Thorstein B. (1898a), "Why is Economics Not an Evolutionary Science?", in idem. (1961).

Veblen, Thorstein B. (1898b), "The Beginnings of Ownership”, in idem. (1934), Essays on Our Changing Order, New York: Viking Press.

Veblen, Thorstein B. (1900a), “Gustav Schmoller"s Economics”, in idem. (1961). 
Veblen, Thorstein B. (1900b), "Preconceptions III", in idem. (1961).

Veblen, Thorstein B. (1904), The Theory of Business Enterprise, reprint 1965, New York: Mentor.

Veblen, Thorstein B. (1908), "On the Nature of Capital I \& II", in idem. (1961).

Veblen, Thorstein B. (1909), "The Limitations of Marginal Utility”, in idem. (1961).

Veblen, Thorstein B. (1914), The Instinct of Workmanship, New York: Augustus M. Kelley.

Veblen, Thorstein B. (1961), The Place of Science in Modern Civilization, New York: Russell and Russell.

Wernerfelt, Birger (1984), "A Resource-Based View of the Firm," Strategic Management Journal, 5, 171-180.

Williamson, Oliver E. (1985), The Economic Institutions of Capitalism, New York: Free Press.

Winter, Sidney G. (1988), "On Coase, Competence, and the Corporation", Journal of Law, Economics, and Organization, 4, 163-180. 


\section{$\mathbf{D}_{\text {anish }} \mathbf{R}_{\text {esearch }} \mathbf{U}_{\text {nit for }} \mathbf{I}_{\text {ndustrial }} \mathbf{D}_{\text {ynamics }}$}

The Research Programme

The DRUID-research programme is organised in 3 different research themes :

\section{- The firm as a learning organisation}

- Competence building and inter-firm dynamics

- The learning economy and the competitiveness of systems of innovation

In each of the three areas there is one strategic theoretical and one central empirical and policy oriented orientation.

\section{Theme A: The firm as a learning organisation}

The theoretical perspective confronts and combines the ressource-based view (Penrose, 1959) with recent approaches where the focus is on learning and the dynamic capabilities of the firm (Dosi, Teece and Winter, 1992). The aim of this theoretical work is to develop an analytical understanding of the firm as a learning organisation.

The empirical and policy issues relate to the nexus technology, productivity, organisational change and human ressources. More insight in the dynamic interplay between these factors at the level of the firm is crucial to understand international differences in performance at the macro level in terms of economic growth and employment.

\section{Theme B: Competence building and inter-firm dynamics}

The theoretical perspective relates to the dynamics of the inter-firm division of labour and the formation of network relationships between firms. An attempt will be made to develop evolutionary models with Schumpeterian innovations as the motor driving a Marshallian evolution of the division of labour.

The empirical and policy issues relate the formation of knowledge-intensive regional and sectoral networks of firms to competitiveness and structural change. Data on the structure of production will be combined with indicators of knowledge and learning. IOmatrixes which include flows of knowledge and new technologies will be developed and supplemented by data from case-studies and questionnaires. 


\section{Theme C: The learning economy and the competitiveness of systems of innovation.}

The third theme aims at a stronger conceptual and theoretical base for new concepts such as 'systems of innovation' and 'the learning economy' and to link these concepts to the ecological dimension. The focus is on the interaction between institutional and technical change in a specified geographical space. An attempt will be made to synthesise theories of economic development emphasising the role of science based-sectors with those emphasising learning-by-producing and the growing knowledge-intensity of all economic activities.

The main empirical and policy issues are related to changes in the local dimensions of innovation and learning. What remains of the relative autonomy of national systems of innovation? Is there a tendency towards convergence or divergence in the specialisation in trade, production, innovation and in the knowledge base itself when we compare regions and nations?

\section{The Ph.D.-programme}

There are at present more than $10 \mathrm{Ph}$.D.-students working in close connection to the DRUID research programme. DRUID organises regularly specific Ph.D-activities such as workshops, seminars and courses, often in a co-operation with other Danish or international institutes. Also important is the role of DRUID as an environment which stimulates the Ph.D.-students to become creative and effective. This involves several elements:

- access to the international network in the form of visiting fellows and visits at the sister institutions

- participation in research projects

- access to supervision of theses

- access to databases

Each year DRUID welcomes a limited number of foreign Ph.D.-students who wants to work on subjects and project close to the core of the DRUID-research programme.

\section{External projects}

DRUID-members are involved in projects with external support. One major project which covers several of the elements of the research programme is DISKO; a comparative analysis of the Danish Innovation System; and there are several projects involving international co-operation within EU's 4th Framework Programme. DRUID is open to host other projects as far as they fall within its research profile. Special attention is given to the communication of research results from such projects to a wide set of social actors and policy makers. 


\section{DRUID Working Papers}

96-1 Lundvall, Bengt-Åke: The Social Dimension of the Learning Economy. (ISBN 87-7873-000-7)

96-2 Foss, Nicolai J.: Firms, Incomplete Contracts and Organizational Learning. (ISBN 87-7873-001-5)

96-3 Dalum, Bent and Villumsen, Gert:Are OECD Export Specialisation Patterns 'Sticky?' Relations to the Convergence-Divergence Debate. (ISBN 87-7873-002-3)

96-4 Foss, Nicolai J: Austrian and Post-Marshallian Economics: The Bridging Work of George Richardson. (ISBN 87-7873-003-1)

96-5 Andersen, Esben S., Jensen, Anne K., Madsen, Lars and Jørgensen, Martin: The Nelson and Winter Models Revisited: Prototypes for ComputerBased Reconstruction of Schumpeterian Competition. (ISBN 87-7873-005-8)

96-6 Maskell, Peter: Learning in the village economy of Denmark. The role of institutions and policy in sustaining competitiveness. (ISBN 87-7873-006-6)

96-7 Foss, Nicolai J. \& Christensen, Jens Frøslev: A Process Approach to Corporate Coherence. (ISBN 87-7873-007-4)

96-8 Foss, Nicolai J.: Capabilities and the Theory of the Firm. (ISBN 87-7873-008-2)

96-9 Foss, Kirsten: A transaction cost perspective on the influence of standards on product development: Examples from the fruit and vegetable market. (ISBN 877873-009-0)

96-10 Richardson, George B.: Competition, Innovation and Increasing Returns. (ISBN 87-7873-010-4)

96-11 Maskell, Peter: Localised low-tech learning in the furniture industry. (ISBN 87-7873-011-2)

96-12 Laursen, Keld: The Impact of Technological Opportunity on the Dynamics of Trade Performance. (ISBN 87-7873-012-0)

96-13 Andersen, Esben S.: The Evolution of an Industrial Sector with a Varying Degree of Roundaboutness of Production. (ISBN 87-7873-013-9) 
96-14 Dalum, Bent, Laursen, Keld \& Villumsen, Gert: The Long Term Development of OECD Export Specialisation Patterns: De-specialisation and "Stickiness" (ISBN 87-7873-014-7)

96-15 Foss, Nicolai J.: Thorstein B. Veblen: Precursor of the Competence-Based Approach to the Firm (ISBN 87-7873-015-5)

\section{Information for subscribers.}

Subscription price for 1996 is $600 \mathrm{DKR}$ (about 20 papers). The rate for single issues is $40 \mathrm{DKR}$. It is possible to make a commitment to an exchange of papers from related departments or research teams. All correspondence concerning the DRUID Working Papers should be send to:

Mette Madsen

Fibigerstræde 4, DK-9220 Aalborg OE

Tel. 45981542 11-2945

Fax. 4598156013

E-mail:mm@business.auc.dk 